\title{
Differentiation of benign from malignant cervical lymphadenopathy by ultrasonography in children
}

\author{
Ömer Kartal ${ }^{a}$, M.D., Erman Ataş ${ }^{a}$, Assoc. Prof., and Orhan Gürsel ${ }^{a}$, Assoc. Prof.
}

\begin{abstract}
Introduction. The mostcommon causes of cervical lymphadenopathy (LAP) are inflammatory and reactive conditions; only a small proportion have serious pathology, such as malignancy. The objective of this study was to evaluate the relationship between USG findings and histopathological diagnosis of the cervical LAP. PopulationandMethods. This retrospectivestudy comprised the cases of cervical LAP in patients aged under 20 years old followed in our center between January 2007 to December 2016. Based on pathology reports, we divided the patients into two groups: benign and malignant. Pathology results and USG findings were compared.

Results. After the analyze of the histopathological results and USG findings, 107 patients with persistent cervical LAP (44 malignant; 63 benign) wereincluded in thestudy. Mean age of malignant and benign group were $14 \pm 6.1 ; 11.9 \pm 4.8$ years, respectively. Hilar vascularity for benign LAP was highly statistically significant $(P<0.0001)$ and peripheral flow and mixed vascularity for malignant LAP were also statistically significant $(p<0.05)$. There was not a significant difference in the maximum diameter $(27.3 \pm 11.1 \mathrm{~mm}$ and $29.8 \pm 12.3 \mathrm{~mm}$, respectively), however, there was a significant difference in the minimum diameter between benign and malignant groups $(13.7 \pm 7.3 \mathrm{~mm}$ and $18.7 \pm 8.8 \mathrm{~mm}$, respectively). Conclusions. The present study suggests that there is a relationship between US and biopsy findings for the differentiation of benign from malignant LAP, especially in terms of nodal hilus and intranodal vascular pattern.

Keywords: children, fine-needleaspiration, intranodal necrosis, lymphadenopathy, ultrasonography.
\end{abstract}

a. Gülhane Training and Research Hospital, Division of Pediatric Hematology and Oncology, Ankara, Turkey

E-mail address:

Ömer Kartal, M.D.:

dr.omerkartal@hotmail. com

Funding:

None

Conflict of interest:

None.

Received: 10-1-2018

Accepted: 6-4-2019 http: / / dx.doi.org/ 10.5546/ aap.2020.eng.11

To cite: Kartal Ö, Ataş E, Gürsel O. Differentiation of by ultrasonography in children. Arch Argent Pediatr 2020;118(1):11-17.

\section{INTRODUCTION}

Many different conditions may cause cervical lymphadenopathy (LAP), such as viral or bacterial infections, tuberculosis, toxoplasmosis, cat-scratch disease, Kikuchi's disease, collagen vascular benign from malignant cervical lymphadenopathy disease and neoplasia. ${ }^{1}$ However, the most common causes of LAP are inflammatory and reactive conditions, only a small proportion has serious pathology, such as malignancy. ${ }^{2}$ Against this small proportion, many parents may be excessively worried about to enlarged lymph node, because of this association.

Fine needle aspiration (FNA) has a substantial role in the diagnosis of cervical lymphadenopathies. ${ }^{3}$ However, this diagnostic procedure has its limitations. For example, FNA has a high false-negative rate associated with obtaining a proper tissue specimen for histopathology and children always need sedation or general anesthesia. There is also a potential risk of spreading infection especially because of the mycobacterial lymphadenitis. ${ }^{4}$

Excision and histopathological evaluation of the LAP is the gold standard method for the diagnosis. ${ }^{3}$ However, the physician should choose the right time to prevent unnecessary surgery and treatment delay for improving outcomes.

Ultrasonography (USG) is a primary diagnostic modality in the assessment of cervical LAP because USG is cost-effective, noninvasive, involves no radiation and easily accessible method and it has also a high sensitivity, up to $96.8 \%$ for detecting malignant cervical LAP in patients with cancer. ${ }^{5}$ We can evaluate size, shape, site, border, hilus, echogenicity, adjacent softtissue edema, vascular pattern and intranodal necrosis of the cervical lymph nodes. ${ }^{6}$

The objective of this study was to evaluate the relationship between USG findings and histopathological diagnosis of the cervical LAP. 


\section{MATERIALS AND METHODS}

This retrospective study comprised the cases of cervical LAP in patients under 20 years old who were followed at the Department of Pediatric Oncology at the Gülhane Training and Research Hospital from January 2007 to December 2016. Information of the patients was accessed by way of the electronic medical recording system and patients' files. Based on pathology reports, we divided the patients into two groups: Benign and malignant. Furthermore, we compared the pathology results and USG findings.

The children who had an enlarged cervical LAP for more than 4-6 weeks and unresponsive to initial antibiotic treatment were considered "persistent' and the biopsy was performed in patients with clinical suspicion (e.g., fixed, hard or rubbery nodes) and USG findings (e.g., non-reactive, conglomerate nodes) related to malignancy. The children who were performed biopsy and USG because of persistent cervical LAP were included in the study. The patients with missing data were excluded. Ultrasonograms were obtained with model HDI 5000, 7- to $12 \mathrm{MHz}$ (Philips Medical Systems, Bothell, WA). The following US findings of cervical lymph nodes were analyzed: Size, long axis/short axis ratio, shape (oval, round), border sharpness (sharp, unsharp), hilum (wide, narrow, and absent), echogenicity (homogeneous, heterogeneous), conglomerate (present, absent), necrosis (present, absent) and intranodal vascular pattern (central, peripheral, mixed and absent).

Lymph node size was assessed by measuring the largest and smallest diameters on the ultrasound screen and was calculated long axis/ short axis ratio. LAP was separated into 2 groups according to their $\mathrm{L} / \mathrm{S}$ ratio: oval $(\mathrm{L} / \mathrm{S}$ ratio $\geq 2)$ and round $(\mathrm{L} / \mathrm{T}$ ratio $<2)$. A nodal mass that is greater than $6 \mathrm{~cm}$ was accepted as bulky lesion. The vascular pattern of cervical LAP was divided into four groups, according to the location of the vascularity: Central, peripheral, mixed (the presence of central and peripheral flow signals) and no flow or absence of vascular signals within the lymph nodes.

The study protocol was approved by the Medical Ethics Committee of Keçiöğren Training and Research Hospital and conducted in accordance with the ethical principles described by the Declaration of Helsinki.

\section{Statistical analysis}

The data were evaluated with SPSS (Statistical Package for Social Sciences) 21.0 program for Windows. Continuous variables were measured as mean and standard deviation. The normality of the distribution of continuous variables was confirmed by Kolmogorov-Smirnov test. Independent $t$ and chi square tests were used to evaluate comparisons between the groups. A $p$-value $<0.05$ was considered significant.

\section{RESULTS}

In this retrospective study, files of a total of 1100 patients younger than 20 years of age with cervical LAP who were referred to Department of Pediatric Oncology between January 2007 and December 2016 were evaluated and we detected 107 cases ( 63 benign; 44 malignant) who were performed biopsy and USG.

The incidence of malignant LAP was significantly higher in the supraclavicular and posterior cervical regions $(70.4 \%$ versus $29.6 \%$ ), $(\mathrm{p}<0.05)$. Conversely, benign LAP was found more often in the submandibular and jugular regions $(68.2 \%$ versus $31.8 \%),(p<0.05)$. The clinical and imaging characteristics of benign and malignant cervical LAP were listed in Table 1, 2.

\section{Nodal size}

The long axis diameter of malignant group (mean \pm SD) was $29.8 \pm 12.3 \mathrm{~mm}$ (range, 9-55 $\mathrm{mm}$ ). The long axis diameter of benign group (mean $\pm \mathrm{SD}$ ) was $27.3 \pm 11.1 \mathrm{~mm}$ (range, 13$55 \mathrm{~mm}$ ). There was not a significant difference in the maximum diameter between malignant and benign group ( $p>0.05)$. The short axis diameter of malignant group (mean \pm SD) was $18.7 \pm 8.8 \mathrm{~mm}$ (range, $6-36 \mathrm{~mm}$ ). The short axis diameter of benign group (mean \pm SD) was $13.7 \pm 7.3 \mathrm{~mm}$ (range, 5.2-30 $\mathrm{mm}$ ). There was a significant difference in the minimum diameter between malignant and benign group $(\mathrm{p}<0.05)$, (Figure 1).

\section{Nodal shape}

In 34 of 63 benign LAP $(54.1 \%)$, L/S ratio was 2 or greater and in 29 of 63 benign LAP $(45.9 \%)$, $\mathrm{L} / \mathrm{S}$ ratio was less than 2 . In 36 of 44 malignant LAP $(81.8 \%)$, L/S ratio was less than 2 , whereas only in 8 of 44 malignant LAP $(18.2 \%)$, L/S ratio was 2 or greater. The differences in distribution of malignant and benign LAP in two L/S groups were statistically significant $(\mathrm{p}<0.05)$, (Figure 2$)$. 


\section{Nodal flow}

Color flow signals were detected in 40 of 44 malignant LAP $(90.9 \%)$. Seventeen $(38.6 \%)$ LAP showed peripheral flow, 15 (34.1\%) LAP showed mixed vascularity, $8(18.2 \%)$ LAP showed hilar vascularity and $4(9.1 \%)$ LAP showed no flow. The vascularity was detected in all 63 benign LAP (100\%). Fifty-seven (90.5\%) LAP showed hilar vascularity, 3 (4.8\%) LAP showed peripheral flow and $3(4.8 \%)$ LAP showed mixed vascularity. In this study, hilar vascularity for benign LAP was highly statistically significant $(p<0.0001)$. Peripheral flow and mixed vascularity for malignant LAP were statistically significant $(p<0.05)$. There was also a statistically significant difference between benign and malignant groups for vascular pattern $(\mathrm{p}<0.05)$.
TABLE 2. Distribution of the cases according to the histopathologic diagnosis

\begin{tabular}{lcc}
\hline Diagnoses & Patients (n) & $\%$ \\
\hline Benign & 48 & 76.2 \\
$\quad$ Reactive LAP & 7 & 11.1 \\
Tuberculosis & 4 & 6 \\
Toxoplasmosis & 2 & 3.2 \\
Castleman's disease & & \\
Histiocytic necrotizing & 1 & 1.6 \\
Lymphadenitis (Kikuchi) & 1 & 1.6 \\
Fibrosis & & \\
Malign & 20 & 45.4 \\
Hodgkin's lymphoma & 13 & 29.5 \\
Non-Hodgkin's lymphoma & 3 & 6.8 \\
Leukemia & 2 & 4.5 \\
Rhabdomyosarcoma & 2 & 4.5 \\
Thyroid carcinoma & 1 & 2.3 \\
Basal cell adenocarcinoma & 1 & 2.3 \\
Tongue carcinoma & 1 & 2.3 \\
Paraganglioma & 1 & 2.3 \\
Osteosarcoma &
\end{tabular}

TABLE 1. Comparison of the clinical and imaging characteristics of benign and malignant cervical LAP $(n=107)$

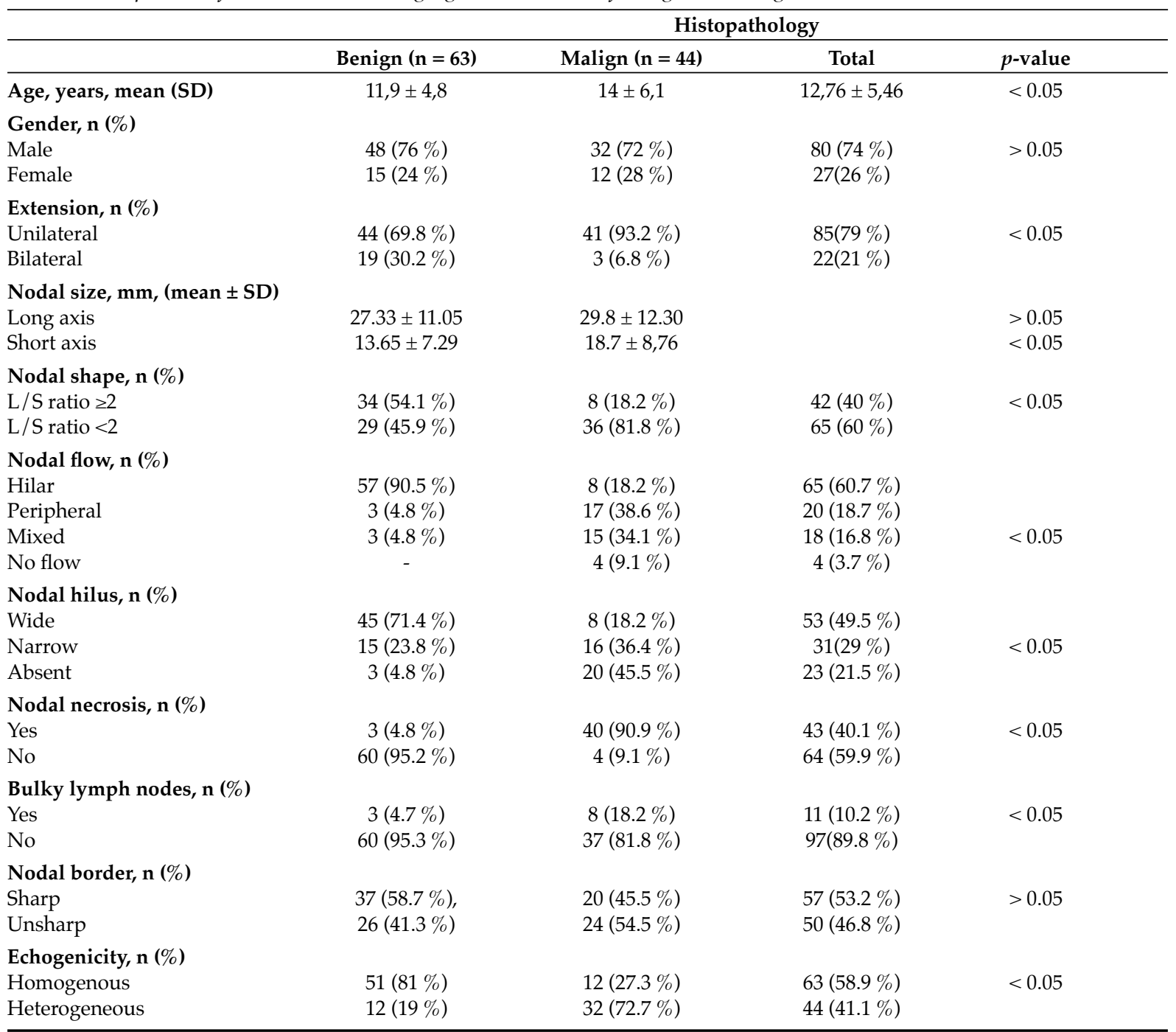




\section{Nodal hilus}

In 45 of 63 benign LAP (71.4\%), a wide central hilus was found and $15(23.8 \%)$ benign LAP had narrow hilus and in $3(4.8 \%)$ no hilus was detected. In 20 of 44 malignant LAP (45.5\%), hilus was not detected and $16(36.4 \%)$ malignant LAP had narrow hilus and in $8(18.2 \%)$ a wide central hilus was detected. The study showed that wide central hilus for benign nodes and absence of hilum for malignant nodes were highly significant parameters $(p<0.0001)$. There was also a statistically significant difference between benign and malignant groups for LAP hilus $(\mathrm{p}<0.05)$.

\section{Nodal necrosis}

Out of 44 malignant LAP, 40 (90.9\%) nodes showed necrosis and $4(9.1 \%)$ nodes hadn't any necrosis. out of 63 benign LAP, $60(95.2 \%)$ nodes had no necrosis and only $3(4.8 \%)$ nodes had necrosis. There was a statistically significant difference between benign and malignant groups for intranodal necrosis $(p<0.05)$.

\section{Bulky lymph nodes}

Out of 44 malignant LAP, we found $32(72.2 \%)$ bulky nodes (conglomerate) and $12(27.8 \%)$ nodes had not bulky lesion. Out of 63 benign LAP, $43(68.3 \%)$ nodes had not bulky lesion and 20 $(31.7 \%)$ nodes had bulky lesion. There was a statistically significant difference between benign and malignant groups for bulky lesion $(\mathrm{p}<0.05)$.

\section{Nodal border}

In 37 of 63 benign LAP (58.7\%), a sharp border was found and $26(41.3 \%)$ benign LAP had an unsharp border. In 24 of 44 malignant

FIGURE 1. Mean values of the long and short axis diameter which belongs to benign and malignant groups

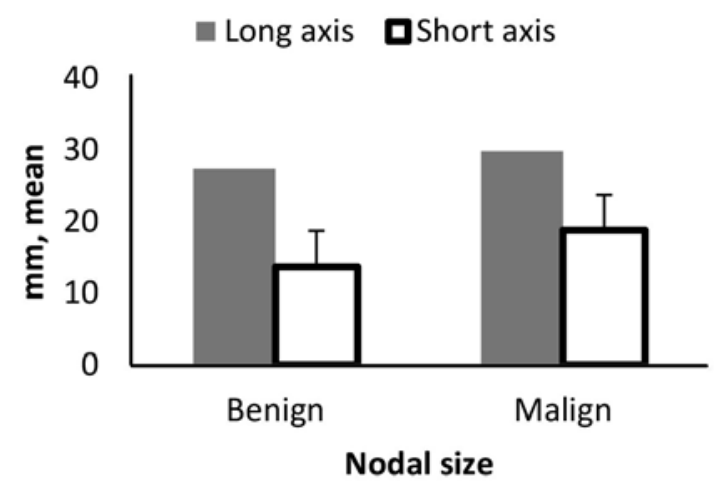

LAP $(54.5 \%)$, an unsharp border was found and $20(45.5 \%)$ malignant LAP had a sharp border. There was not a statistically significant difference between benign and malignant groups for sharp border $(p>0.05)$.

\section{Echogenicity of nodes}

Of the 63 benign LAP, $51(81 \%)$ nodes showed homogenous echotexture and $12(19 \%)$ heterogeneous echotexture. Of the 44 malignant LAP, $32(72.7 \%)$ showed heterogeneous echotexture and $12(27.3 \%)$ homogenous echotexture. There was a statistically significant difference between benign and malignant groups for echogenicity of LAP $(p<0.05)$.

\section{DISCUSSION}

The enlarged cervical LAP is a general clinical problem in children. However, we rarely encounter malignancy in this age group. Özkan et al., assessed histopathological LAP result of 71 patients and reported Hodgkin lymphoma was the most common neoplasm $(26.7 \%)$ in malignant group. In benign group, the most common lesion was reactive LAP $(28.2 \%) .{ }^{7}$ Likewise, in another study, Mbise RL et al., analyzed excisional lymph node biopsy of 257 children and reported Hodgkin lymphoma was the predominant cause $(34.5 \%)$ of malignant group and reactive LAP ratio was found as $20.6 \%$ in benign group 8 . In our study, we observed reactive LAP $(76.2 \%)$ most frequently in benign group and, in malignant group, Hodgkin lymphoma was the most common neoplasm (45.5\%). Our findings are in accordance with these results. However, we found higher rates and we thought it was probably because of the case selection.

FIGURE 2. Mean values of $L / S$ ratios which belongs to benign and malignant groups $(p<0.05)$

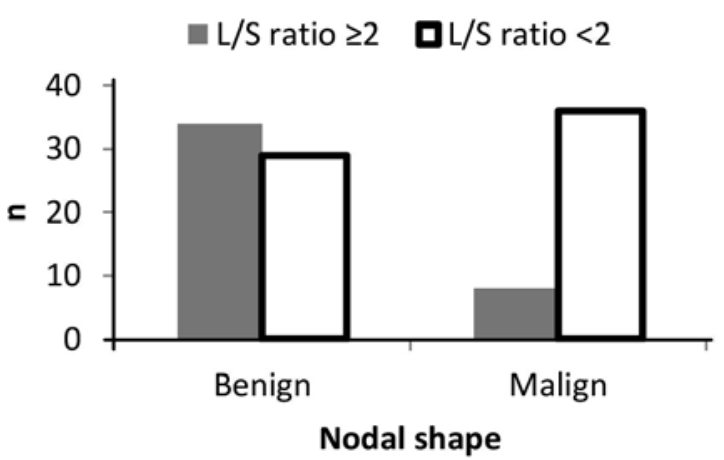


The laterality of benign and malignant LAP in children is controversial. ${ }^{9}$ Sarsu et al., reported that $91.31 \%$ of the pediatric patients with benign lesion showed unilateral LAP whereas $8.68 \%$ of them presented with bilateral ${ }^{10}$. In another study, carried out by Celenk et al., in malignant group, unilateral/bilateral ratio was $57.4 \% / 42.6 \% .^{3}$ In contrast to these results, Gwili et al., showed that $81 \%$ of the children with benign LAP and $92.7 \%$ of malignant LAP showed bilateral involvement. ${ }^{11}$ In our study, $69.8 \%$ of the children with benign LAP showed unilateral involvement whereas $30.2 \%$ of them presented with bilateral and in malignant group, unilateral / bilateral ratio was $93.2 \% / 6.8 \%$. We thought that the case selection and study design may be the reason of this discrepancy.

The nodal size is also a suspicious criterion for differentiating benign from malignant LAP today and in the neck, different cutoff points are proposed for size in different studies. ${ }^{12-14} \mathrm{We}$ found statistically significant difference between benign and malignant LAP in terms of their minimum diameter. However, there was not any statistically significant difference between benign and malignant LAP in terms of their maximum diameter. Oguz et al., detected a maximum diameter of more than $2 \mathrm{~cm}$ as the appropriate limit with which to distinguish malignant LAP from benign LAP. ${ }^{15}$ Additionally, Kuna et al., found a minimum diameter of more than $1.2 \mathrm{~cm}$ as the appropriate limit for differentiating benign from malignant LAP and according to VargasVallejo et al., the size of LAP bigger than $3 \mathrm{~cm}$ was the most appropriate difference between malignant and benign LAP. ${ }^{16,17}$

Some authors advocate that malignant nodes have usually round shape and some benign conditions such as infectious mononucleosis, bacterial lymphadenitis, tuberculosis, Kawasaki disease, catscratch disease and normal submandibular/parotid lymph nodes could also have round shape. ${ }^{6,12,18}$ Therefore, the shape of cervical LAP cannot be a single criterion in the diagnosis by USG. According to the study done by Yu et al, in 21 of 44 benign LAP $(47.7 \%)$, $\mathrm{L} / \mathrm{S}$ ratio was $\leq 2$, and in 27 of 50 malignant LAP $(54.0 \%)$, the ratio was $\leq 2$. They found a low specificity and accuracy related to L/S ratio. ${ }^{19}$ Whereas, in our study, we observed statistically significant difference between benign and malignant LAP in terms of their nodal shape. These differences may be due to the sample size and diverse characteristics of the study participants.
Benign LAP could have a marked hilar vascularity because of the increased vessel diameter and blood flow. ${ }^{20}$ Additionally, malignant LAP could also have a hilar vascularity because of the presence of micrometastases at the early stage of malignancy. ${ }^{21}$ In a study done by Dangore et al., $79 \%$ of benign and $5 \%$ of malignant LAP showed hilar vascularity. ${ }^{22}$ In our study of 107 LAP, malignant $18.2 \%$ and benign $76 \%$ showed hilar vascularity. The $p$ value for this criterion was less than 0.0001 , which showed the association to be very significant.

Malignant LAP may cause peripheral/ mixed vascularity because of the destruction of hilar vascularity by tumour cells. ${ }^{22}$ In a study carried out by Sindhoori et al., in malignant group, peripheral/mixed vascularity ratios were $8 \% / 76 \%$ and in another study done by Na DG et al., were $6 \%$ and $85 \%$ respectively. ${ }^{20,23}$ Our findings are consistent with these results. In our malignant group, peripheral/mixed vascularity ratios were $38.6 \%$ and $34.1 \%$ respectively. The $p$ value for these criteria was also showed the association to be significant. Our study had different ratios from these studies and we thought it was probably because of the case selection and duration of illness.

The invasion of the lymph node with the malignant cells causes early distortion of internal nodal architecture and resulting in narrowing or absence of hilum..$^{20}$ The incidence of wide hilum increases with the inflammatory stimulus and age which is probably related to the increased fatty deposition in the lymph node. ${ }^{12,24}$ Vasallo et al., found that $58 \%$ of benign LAP showed a wide central hilus, $35 \%$ showed a narrow hilus and $8 \%$ no hilus, $48 \%$ of malignant LAP showed no hilus, $46 \%$ showed a narrow hilus and $6 \%$ a wide central hilus. ${ }^{25}$ In our study majority of benign LAP showed wide hilum where as in majority of malignant LAP showed absent or narrow hilum and it was statistically significant. However, in a study, $64 \%$ of tubercular LAP also showed absent hilus and $21 \%$ showed narrow hilus. ${ }^{20}$ Therefore, we believe that wide, narrow or absence of a hilus should not be used as a single criterion for evaluating cervical LAP.

Intranodal necrosis is a pathologic condition. It has been reported in some cases, such as tuberculosis, inflammatory and malignant diseases. ${ }^{26}$ Reshma Vj et al., detected that $36 \%$ of both malignant and tubercular LAP showed intranodal necrosis and they did not detect any necrosis in benign group ${ }^{14}$. In our study, $90.9 \%$ 
of malignant LAP showed intranodal necrosis, which were all malignant on histopathological evaluation. Benign lymph nodes showed $4.8 \%$ intranodal necrosis. The $\mathrm{p}$ value showed significant association.

Benign lymph nodes usually tend to have unsharp border because of edema or inflammation of the surrounding tissues and malignant lymph nodes usually tend to have sharp border. Because tumour infiltration causes an increase in the difference between LAP and surrounding tissues. ${ }^{22}$ However, Ahuja et al., found that $40 \%$ of malignant LAP and $30 \%$ of benign LAP showed unsharp borders. According to their proposal, border sharpness is not useful in differential diagnosis. ${ }^{6}$ In our study, $54.5 \%$ of malignant LAP and $41.3 \%$ of benign LAP showed unsharp borders. Our result was compatible with this study.

Malignant LAP could have heterogeneous echogenic structure because of the intranodal cystic degeneration and calcifications. ${ }^{27}$ According to the study conducted by Toriyabe et al., $89 \%$ of malignant LAP had heterogeneous echotexture structure and $90 \%$ of benign LAP had homogenous echotexture structure. ${ }^{28}$ Our findings were similar with these results and the $p$ value was statistically significant.

A nodal mass, which is greater than $6 \mathrm{~cm}$, is generally defined as bulky lesion. ${ }^{29} \mathrm{Al} \mathrm{Kadah}$ et al., found that $25 \%$ of malignant LAP had bulky lesion and it was is statistically significant. ${ }^{30}$ We observed similar result with this study and it was statistically significant.

There are several limitations to this study. First, this study was a retrospectively designed. Second, the results of study were obtained from a single center with a relatively small sample size. Third, we evaluated only cervical region to determine the relationship between US and biopsy findings for the differentiation of benign from malignant LAP.

\section{CONCLUSION}

Cervical LAP is a common problem in the childhood and it is mostly caused by infections. However, it is not always easy to exclude malignancy by physical examination. The present study suggests that there is a relationship between US and biopsy findings for the differentiation of benign from malignant LAP, especially in terms of nodal hilus and intranodal vascular pattern.

\section{Acknowledgments}

We would like to thank Ayşe Tuğba Kartal, M.D., for his valuable collaboration with the for processing and putting together the data.

We appreciate all other colleagues for helping us in data collection.

\section{REFERENCES}

1. Oh KH, Woo JS, Cho JG, Baek SK, et al. Efficacy of ultrasound-guided core needle gun biopsy in diagnosing cervical lymphadenopathy. Eur Ann Otorhinolaryngol Head Neck Dis. 2016; 133(6):401-4.

2. Locke R, Comfort R, Kubba H. When does an enlarged cervical lymph node in a child need excision? A systematic review. Int J Pediatr Otorhinolaryngol. 2014; 78(3):393-401.

3. Celenk F, Gulsen S, Baysal E, Aytac I, et al. Predictive factors for malignancy in patients with persistent cervical lymphadenopathy. Eur Arch Otorhinolaryngol. 2016; 273(1):251-6.

4. Sahai S. Lymphadenopathy. Pediatr Rev. 2013; 34(5):216-27.

5. Ryu KH, Lee KH, Ryu J, Baek HJ, et al. Cervical lymph node imaging reporting and data system for ultrasound of cervical lymphadenopathy: a pilot study. AJR Am J Roentgenol. 2016; 206(6):1286-91.

6. Ahuja AT, Ying M. Sonographic evaluation of cervical lymph nodes. AJR Am J Roentgenol. 2005; 184(5):1691-9.

7. Özkan EA, Göret CC, Özdemir ZT, Yanik S, et al. Evaluation of peripheral lymphadenopathy with excisional biopsy: six-year experience. Int J Clin Exp Pathol. 2015; 8(11):15234-9.

8. Mbise RL. Peripheral lymphadenopathy in children in Dar es Salaam, Tanzania. A study from biopsy material. Ann Trop Paediatr. 1984; 4(2):83-5.

9. Ying M, Bhatia KS, Lee YP, Yuen HY, Ahuja AT. Review of ultrasonography of malignant neck nodes: greyscale, Doppler, contrast enhancement and elastography. Cancer Imaging. 2014; 13(4):658-69.

10. Sarsu SB, Sahin K. A retrospective evaluation of lymphadenopathy in children in a single center's experience. $J$ Pak Med Assoc. 2016; 66(6):654-7.

11. Gwili NM, Hadi MA, Eldin AN, Hassab HM, et al. Lymphadenopathy in a series of Egyptian pediatric patients and the role of pathology in the diagnostic workup. Pediatr Dev Pathol. 2014; 17(5):344-59.

12. Ying M, Pang BS. Three-dimensional ultrasound measurement of cervical lymph node volume. Br J Radiol. 2009; 82(980):617-25.

13. Ying M, Ahuja A, Metreweli C. Diagnostic accuracy of sonographic criteria for evaluation of cervical lymphadenopathy. J Ultrasound Med. 1998; 17(7):437-45.

14. Vj R, A SA, Mufeed A, Vadivazhagan, Isaac JK. Characterization of cervicofacial lymphnodes - a clinical and ultrasonographic study. J Clin Diagn Res. 2014; 8(8):25-38.

15. Oguz A, Karadeniz C, Temel EA, Citak EC, Okur FV. Evaluation of peripheral lymphadenopathy in children. Pediatr Hematol Oncol. 2006; 23(7):549-61.

16. Kuna SK, Bracic I, Tesic V, Kuna K, et al. Ultrasonographic differentiation of benign from malignant neck lymphadenopathy in thyroid cancer. J Ultrasound Med. 2006; 25(12):1531-7.

17. Vargas-Vallejo MdelP, Álvarez-Solís RM, Juárez-Quintal M, Bulnes-Mendizábal D, Quero-Hernández A. Factores clínicos predictores de malignidad en biopsia de ganglios cervicales en pediatría. Rev Med Inst Mex Seguro Soc. 2007; 45(4):389-94. 
18. Ahuja AT, Ying M, Ho SY, Antonia G, et al. Ultrasound of malignant cervical lymph nodes. Cancer Imaging. 2008; 8:48-56.

19. Yu M, Liu Q, Song HP, Han ZH, et al. Clinical application of contrast-enhanced ultrasonography in diagnosis of superficial lymphadenopathy. J Ultrasound Med. 2010; 29(5):735-40.

20. Komma S, Munirathna Nb, Sureshc TN, Hegde P, Kumar N. Evaluation of cervical lymphadenopathy by ultrasound in comparision with FNAC. Int J Biol Med Res. 2014; 5(4):4448-54.

21. Steinkamp HJ, Mueffelmann M, Böck JC, Thiel T, et al. Differential diagnosis of lymph node lesions: a semiquantitative approach with color Doppler ultrasound. Br J Radiol. 1998; 71(848):828-33.

22. Dangore SB, Degwekar SS, Bhowate RR. Evaluation of the efficacy of colour Doppler ultrasound in diagnosis of cervical lymphadenopathy. Dentomaxillofac Radiol. 2008; 37(4):205-12.

23. Na DG, Lim HK, Byun HS, Kim HD, et al. Differential diagnosis of cervical lymphadenopathy: usefulness of color Doppler sonography. AJR Am J Roentogenol. 1997; 168(5);1311-6.
24. Som PM. Lymph nodes of the neck. Radiology. 1987; 165(3):593-600.

25. Vassallo P, Wernecke K, Roos N, Peters PE. Differentiation of benign from malignant superficial lymphadenopathy: the role of high resolution US. Radiology. 1992; 183(1):21520.

26. Shozushima M, Suzuki M, Nakasima T, Yanagisawa Y, et al. Ultrasound diagnosis of lymph node metastasis in head and neck cancer. Dentomaxillofac Radiol. 1990; 19(4):165-70.

27. Takashima S, Sone S, Nomura N, Tomiyama N, et al. Nonpalpablelymph nodes of the neck: assessment with US and US-guided fine-needle aspiration biopsy. J Clin Ultrasound. 1997; 25(6):283-92.

28. Toriyabe Y, Nishimura T, Kita S, Saito Y, Miyokama N. Differentiation between benign and metastatic cervical lymph nodes with ultrasound. Clin Radiol. 1997; 52(12):927-32.

29. Roberts KB, Younes A, Hodgson DC, Advani R, et al. ACR Appropriateness Criteria ${ }^{\circledR}$ Hodgkin Lymphoma-Unfavorable Clinical Stage I and II. Am J Clin Oncol. 2016;39(4):38495.

30. Al Kadah B, Popov HH, Schick B, Knöbber D. Cervical lymphadenopathy: study of 251 patients. Eur Arch Otorhinolaryngol. 2015; 272(3):745-52. 